\title{
Selo, seljaci/poljoprivrednici i seljani pod lupom znanstvenika
}

\author{
Biblioteka Pograničje, 5., 6., 7., i 8. knjiga, Mašinski fakultet, Niš i \\ Prometej, Novi Sad, 2014.
}

U Nišu je prije nekoliko godina pokrenut jedninstveni znanstvenoistraživački projekt pod nazivom Održivost identiteta Srba i nacionalnih manjina u pograničnim opštinama istočne i jugoistočne Srbije, a financira ga Ministarstvo prosvete, nauke i tehnološkog razvoja Republike Srbije. Inicijator i voditelj istraživanja je priznati i svestrani znanstvenik te profesor na Mašinskom fakultetu Univerziteta u Nišu, prof. dr. sc. Dragoljub B. Đorđević. Ovaj se znanstvenik dugi niz godina bavi sociološkim i religijskim istraživanjima, proučava život i običaje Roma, a istraživao je i život krčme - kafanski život pa je za knjigu Kazuj krčmo Džerimo: periferijska kafana i oko nje dobio i nagradu "Desimir Tošić" 2011. godine. Osim u Nišu i Beogradu, svoje je radove objavljivao i u zagrebačkoj "Reviji za sociologiju", splitskim "Pogledima" te sarajevskim "Opredjeljenjima". Sebe predstavlja kao sociologa religije, romologa i kafanologa, a na Mašinskom fakultetu predaje sociologiju kulture i morala te profesionalnu etiku inženjera.

Projektom Održivost identiteta Srba i nacionalnih manjina u pograničnim opštinama istočne i jugoistočne Srbije planirano je empirijski istražiti gotovo svaku poru iz društvenoga života i rada seoskih zajednica u šesnaest općina u spomenutom pograničnom području Srbije (na tromedi Bugarske, Makedonije te Kosova). Stoga je u njegovu realizaciju uključena vrsna ekipa znanstvenika najrazličitijeg profila - od sociologa, etnologa i antropologa, ekonomista i agrarnih ekonomista, psihologa, pedagoga, politologa, filozofa, književnika i jezikoslovaca, ekologa, stručnjaka iz fizičke kulture i sporta do stručnjaka iz inženjerijskog menadžmenta.

Rezultati ovoga opsežnoga terenskog istraživanja objedinjeno su objavljivani od godine 2012. do 2014. u nekoliko zbornika radova te jednoj monografiji. Kako je inicijator projekta, dr. Đorđević, ujedno i urednik gotovo svih tih edicija o pograničnim selima Srbije, on je sve te radove uvrstio u bibliotečni niz simboličnog naziva "POgraničje", s kontinuiranim bibliotečnim brojevima. S obzirom da će naša analiza biti usmjerena samo na četiri publikacije iz toga niza, a dosada ih je publicirano preko desetak, držimo vrijednim da ih samo navedemo kako bi se dobio uvid i u ostale aspekte projektnog istraživanja. Kako su mjesta izdanja i izdavači publikacija različiti, navest ćemo ih kao i autore i priređivače edicija.

1. Selo u pograničju / prir. Dragoljub B. Đorđević, Đura Stevanović, Dragan Todorović. - Beograd: Službeni glasnik; Niš: Mašinski fakultet, 2012. 
2. Stariji ljudi u pograničju / prir. Lela Milošević Radulović, Jasmina Petrović, Ivana Ilić Krstić. - Beograd: Službeni glasnik; Niš: Mašinski fakultet, 2013.

3. Ljudi iz pograničja govore / prir. Milan Tasić, Danijela Zdravković, Dejan Krstić. - Vranje: Učiteljski fakultet, 2014.

4. Vašar u pograničju / prir. Dragoljub B. Đorđević, Dragan Todorović, Dejan Krstić. - Novi Sad: Prometej ; Niš: Mašinski fakultet, 2014.

5. Porodično gazdinstvo u pograničju / prir. Dragoljub B. Đorđević, Milovan Vuković. - Novi Sad: Prometej; Niš: Mašinski fakultet, 2014.

6. Đorđević, Dragoljub B.; Uzunović, Slavoljub; Petrović, Vladan: Sirovo borovo: sociološka geneza preševskog Cakanovca. - Novi Sad: Prometej; Niš: Mašinski fakultet, 2014.

7. Uzornik u pograničju / prir. Dragoljub B. Đorđević, Vesna Trifunović, Njegoš Dragović. - Novi Sad: Prometej; Niš: Mašinski fakultet, 2014.

8. Učitelj u pograničju / prir. Marija Jovanović, Vesna Trifunović, Danijela Zdravković. - Novi Sad: Filozofski fakultet, 2014.

9. Proučavanje društvenih pojava: metodološka razmatranja / prir. Jasna Petrović, Dragoljub B. Đorđević. - Niš: Filozofski i Mašinski fakultet, 2014.

10. Biti sociolog sela / prir. Dragoljub B. Đorđević. - Beograd: Srpsko udruženje za sociologiju sela; Niš: Mašinski fakultet, 2014.

11. Selo neveselo: zbornik radova od nacionalnog značaja / prir. Nedeljko Bogdanović. - Novi Sad: Prometej; Niš: Hamimontana ; Mašinski fakultet, 2014.

Svi zbornici u ovoj seriji nose podnaslov zbornik radova vodećeg nacionalnog značaja, što se iščitava s preliminarnih stranica publikacije. Izvan biblioteke "Pograničje" objavljene su još dvije studije na engleskom jeziku:

12. Religion, Religious and Folk. Customs on the Border / eds. Đorđević, D. B.; Gavrilović, D.; Todorović, D. - Niš: Yugoslav Society for the Scientific Study of Religion, 2012.

13. A Priest on the Border / eds. Đorđević, D. B.; Todorović, D.; Jovanović, M. Niš: Yugoslav Society for the Scientific Study of Religion; Faculty of Mechanical Engineering, 2013.

U pripremi su i knjige:

14. Zanatlija u pograničju / prir. Dejan Krstić, Dragoljub B. Đorđević, Suzana Marković Krstić. - Novi Sad: Prometeja; Niš: Mašinski fakultet, 2014.

15. Todorović, Dragan; Đorđević, Dragoljub B.: Zanimljivi Romi. - Niš: Filozofski fakultet, 2015.

16. Đorđević, Dragoljub B.: Sazrevanje predgrađa. - Niš: Mašinski fakultet; Novi Sad: Prometej, 2015.

U daljnjem tekstu prikazat ćemo samo četiri studije koje su nam dostupne. To su: Porodično gazdinstvo u pograničju; Sirovo borovo: sociološka geneza preševskog Cakanovca; Uzornik u pograničju; Selo neveselo. Sve četiri su publicirane u 2014., a ovako smo ih poredali po brojevima bibliotečnog niza "Pograničje". 


\section{Porodično gazdinstvo u pograničju istočne $\mathbf{i}$ jugoistočne Srbije: zbornik radova vodećeg nacionalnog značaja / prir. Dragoljub B. Đorđević, Milovan Vuković. - Novi Sad: Prometej; Niš: Mašinski fakultet, 2014., 324 str. - (Biblio- teka Pograničje; knj. 5)}

U ovom opsežnom zborniku obrađena je socijalno-ekonomska problematika poljoprivrednih obiteljskih gospodarstava u šesnaest općina istraživanoga pograničja - od Velikog Gradišta do Preševa. Dvadeset i pet znanstvenika sudjelovalo je u ovom istraživanju, primjenjujući metode sociološko-etnološke - dubinski intervjui, promatranje, snimanje, iskazi kazivača i sl. U obradi materijala u svakom se prilogu polazi od općih značajki naselja (geografsko-povijesnih, ponekad i od genealogije vlasnika gospodarstva), pa o samom gospodarstvu i njegovim značajkama. Uz konkretno izložene pokazatelje o gospodarstvu i njegovu vrednovanju, veći broj priloga sadrži i originalne iskaze samih proizvođača.

Ne ulazeći u sadržajnu analizu autorskih priloga, ovdje ćemo ih dosljedno ispisati, s napomenom da je svaki od njih opremljen znanstvenim pomagalima: sažecima na srpskom i engleskom jeziku, literaturom, indeksom imena, fotografijama. Na kraju slijede podaci o priređivačima zbornika i autorima. Radovi su ostručeni po UDK, a uz sam naslov priloga navedena je općina promatranoga gazdinstva. Dakle, autori su istraživali različite tipove gospodarstava, od onih zaista uzornih do onih siromašnijih, niskoproduktivnih, sa zastarjelom tehnologijom, do staračkih i planinskih gospodarstava, ili po tipu njihove osnovne proizvodne kulture (npr. kozarstvo, biljna proizvodnja i voćarstvo i sl.). Usput je spomenut i tip tzv. nepoljoprivredničke poljoprivrede, nastale kupovinom malih, usitnjenih parcela, više u cilju rekreativnog bavljenja poljoprivredom.

U predgovoru recenzenta Đure Stevanovića (str. VII-XII) više je dan naglasak na vrste i ukupan ekonomski značaj poljoprivrednih gospodarstava u vrijeme do 1990ih, nego što je komentirao rezultate istraživanja ove vrijedne niške ekipe. Ipak, zaključna mu je misao: "Knjiga je, uz sve svoje manjkavosti uzrokovane upotrebom kvalitativne metodologije, nesumnjivo vredan doprinos srpskoj sociologiji sela. Prinos na koji se dugo čekalo."

2. Đorđević, Dragoljub B.; Uzunović, Slavoljub; Petrović, Vladan: Sirovo borovo: sociološka geneza preševskog Cakanovca: monografija nacionalnog značaja. - Novi Sad: Prometej ; Niš: Mašinski fakultet, 2014., 203 str. - (Biblioteka Pograničje ; knj. 6)

Monografija Sirovo borovo: sociološka geneza preševskog Cakanovca jedina je sociološko-etnološka studija o malom selu Cakanovcu, koja je izrađena za neko selo u okviru ovoga širokokoncipiranog projekta. Istraživanje u ovoj mikrosredini trajalo je punih četiri godine. Konzultirajući Podsetnik za prikupljanje građe (iz 2011.), metodom dubinskog istraživanja, promatranja i promatranja s učestvovanjem, intervjua, audiovizuelnih i fotozapisa, te statističkih podataka, literature i arhivske građe, te uz pomoć seoskih kazivača, trojica su autora istraživali svu problematiku sela u kojemu živi tek 156 žitelja - Srba i Đozgovaca (pravoslavnih Roma) - u izrazito albanskom 
okruženju. Osnovne karakteristike sela su opće siromaštvo: to je do "neizdržljivosti urušeno selo", koje nema zadrugu niti otkupnu stanicu, ima struju (uvedenu 1961.) ali nema vodovod, nema prodavnicu, kavanu ili kafić, pa čak ni fudbalski klub. Ono malo žitelja bavi se poljoprivredom, a tek ih trećina radi na nekim nesigurnim poslovima u Preševu.

Studija je koncipirana u dva dijela. U prvom dijelu, naslovljenom Selo i seljani (str. 17-144), Dragoljub B. Đorđević piše o geografsko-povijesnom značaju Cakanovca koji se pod različitim imenima spominje još iz XV. stoljeća. Potom analizira stanje na jednom uzornom obiteljskom gospodarstvu (Zlatkovici: cakanovačko gazdinstvo za ugled (Preševo)), (str. 41-57). Oslikava društvenu klimu i odnose u Cakanovcu kroz dubinski razgovor sa Dragoljubom Ristićem, čestitim Srbinom koji nije ni nacionalno ni vjerski opterećen (prva mu je žena bila Makedonka, a druga mu je žena Hrvatica iz Splita), koji je argatovao diljem Jugoslavije, da bi se na kraju vratio na očevinu (Draža cakanovački govori, str. 58-79). Analizira i kulturno-prosvjetne prilike u Cakanovcu kroz razgovor sa dvoje intelektualaca - značajnikom/uglednikom - docentom dr. Slavoljubom Uzunovićem, inače profesorom fizičke kulture i sporta (Uglednik Uzun cakanovačko-staničarski, str. 80-92) i cakanovačkom učiteljicom (Cakanovačka učiteljica Vesna Marković, str. 93-104). Na kraju autor piše o starom religijskom običaju/obredu vezanom uz ovaj kraj (Cakanovački sirovari, str. 105-119). Sirovari se uspoređuju s koledarima, a čini ih grupa od 7-9-11 najčešće neoženjenih mladih ljudi koji uoči pravoslavne Nove godine (Vlasuljice) posjećuju domaćinstva i čestitaju im blagdane, a zanoće u zadnjem domaćinstvu kojega posjete. Svoje je tekstove Đorđević obogatio fotografijama, a na kraju je priložio opsežnu literaturu i imenski registar.

U drugom dijelu monografije - naslovljenom Selo i običaji (str. 147-199) - Slavoljub Uzunović i Vladan Petrović oslikavaju seoske narodne običaje i obrede u tri priloga: Lazarice: obredna igra Cakanovčana (str. 147-162), Ne mu je toj ime, takoj ga vikav (str. 163-172), te Cakanovačko groblje (str. 182-195). Međutim, četvrti prilog - Miroslava Todorović - samoća kao sudbina (str. 173-181) - ne spada u kategoriju etnoloških već u kategoriju socioloških radova. U Lazaricama se obrađuje stari narodni običaj koji se prakticira u širem niškom području, ali i u Cakanovcu. Taj se obred izvodi na Lazarevu subotu, sedam dana prije Vaskrsa/Uskrsa. Neki ga vezuju uz legendu po kojoj je knez Lazar prokleo svoje sestre; Crkva ga vezuje uz uskrsnuće kneza Lazara; treći ga smatraju obredom plodnosti i berićeta. Izvodi ga šesteročlana ekipa djevojčica $(2+2+2)$ i jedan dječak, obučenih u narodnu nošnju. $S$ prigodnim pjesmama oni ulaze u selo i domaćinstva, a ovi ih s radošću dočekuju i daruju. Za svaki oblik življenja i prakse u selu postoje i odgovarajuće pjesme, pa se zato lazarice dugo pripremaju za ovaj obred. Autori su od kazivačica u selu prikupili šesnaest prigodnih pjesama. U članku Ne mu je toj ime ... obrađuju se seoski antroponimi, što spada u područje lingvistike, pa autori za svaku seosku obitelj - uz ime i prezime - daju i nadimak. Pritom objašnjavaju kako zapravo nadimci nastaju: od izvedenih skraćenih oblika imena ili prezimena, od nekih karakternih osobina pojedinaca, od nekih zanimanja, a zapravo su dio folklora i redovito se prenose na potomke, pa otuda i ono iz naslova "Ne mu je toj ime, takoj ga vikav". U prilogu o cakanovačkom groblju autori uvodno pišu o naselju i njegovim žiteljima, a potom 
obrađuju kult groblja - kome ono što znači, kako se održava (bilježeći 10 značajki koje govore i o mrtvima ali i o živima), te što se sve može iščitati iz nadgrodnih spomenika (bilježeći čak 11 evidentnih značajki - od bogatsva, profesije, epitafa i sl.). Objašnjavaju da se iz higijensko-sanitarnih razloga groblja izmještaju iz naselja, i to na povišenim lokacijama. Kako je Cakanovac u nizini, groblje mu je udaljeno jedan kilometar, a nema i potrebe za njegovim širenjem, s obzirom na bijelu kugu koja uveliko vlada selom. U prilogu o Miroslavi Todorovi, metodom intervjua autori su prikupili porazna podatke o propasti jedne dobrostojeće obitelji, iza koje je ostala samo jedna starija nasljednica, neudana i bez potomaka. Sama zarađuje sebi za život, kuća (nekad katnica s doksatom) sada je na rubu rušenja. Jedina vedrina u Miroslavinom slučaju jest dobrosusjedski odnos mještana prema njoj i što joj je nećak uvijek pri ruci.

U pohvalama ovoj monografiji o tipičnom selu sa srpske granice, recenzent Andon Kostadinović piše: "Odavno u domaćoj sociologiji sela nismo imali takvu studiju o jednom selu koje zauzima strateški položaj u albanskom okruženju i koje opstaje zahvaljujući činjenici da se meštani drže narodnih i veskih običaja" (citat s poleđine korica).

\section{Uzornik u pograničju istočne i jugoistočne Srbije: zbornik radova vo-} dećeg nacionalnog značaja / prir. Dragoljub B. Đorđević, Vesna Trifunović, Njegoš Dragović. - Novi Sad: Prometej ; Niš: Mašinski fakultet, 2014., 348 str. - (Biblioteka Pograničje ; knj. 8)

Metodom intervjua i priloženim upitnikom za anketirane (objekt istraživanja), autori su prikupili podatke o životu i profesionalnom usmjerenju od šesnaestoro uzornika/ uglednika iz 16 pograničnih općina istočne i jugoistočne Srbije. Namjera im je bila istražiti njihov osobni doprinos široj društvenoj zajednici ali i svome zavičaju. Upitnik s trinaest pitanja uzornicima sastavili su Dragoljub B. Đorđević, Vesna Trifunović i Njegoš Dragović (str. 337-338). U prikupljanju podataka sudjelovalo je dvadeset i troje istraživača, po struci meritornih za razgovor s anketiranim znanstvenikom. A iz samih naslova priloga vidljivo je koji su profili stručnjaka bili obrađeni. Autorski su radovi ponekad vrlo opsežni, s puno iskaza samih uglednika, pribilježenih njihovih biobibliografija ili literature o njima, brojnih fotografija, a na kraju svih napisa priložen je sažetak na srpskom i engleskom jeziku. Svaki je rad stručno kataloški obrađen po UDK. Potom je izrađen imenski registar, a priloženi su i podaci o priređivačima zbornika, te autorima priloga. Uz naslov na koricama priložene su fotografije svih šesnaestero znamenitijih osoba iz pograničja.

U nekim vrijednim općim pohvalama ili zamjerkama autorima zbornika nezaobilazan je hvalevrijedan Predgovor doktora filoloških znanosti, Nedeljka Bogdanovića (str. VII-XIV). U prvom redu on napominje da su autori zbornika ukazali na atraktivnost kreativnog izraza anketiranih uzornika, inače ljudi s netipičnom sudbinom. Ukazali su i na utjecaj pograničja na razvoj njihova talenta te povratan utjecaj uzornika na svoj zavičaj. No u slučaju povratnog utjecaja na zavičaj, Bogdanović drži da su oni više informatori nego sudionici u realnim problemima svojih matičnih sredina. Njima je zavičaj više duhovni (selo u srcu) nego socijalni realni prostor, i vraćaju mu 
se najčešće kao turisti. Svoja znanstveno-stručna postignuća više su namijenili široj javnosti, a tek posredno i svome zavičaju. Upućene su i neke zamjerke primijenjenoj metodologiji, što odaje dojam šablonizacije. No stvaran doprinos ovoga zbornika jest u otkrivanju znamenitijih osoba iz malih sredina za koje se inače nije čulo. S pravom se očekuje da će ovi radovi pobuditi interes javnosti za sredine iz kojih oni potječu.

4. Selo neveselo: zbornik radova od nacionalnog značaja / prir. Nedeljko Bogdanović. - Novi Sad: Prometej ; Niš: Hamimontana; Mašinski fakultet, 2014., 140 str. - (Biblioteka Pograničje ; knj. 10)

Ova je knjiga nastala na vrlo interesantan način. Naime, njezin urednik Nedeljko Bogdanović, inače doktor filoloških nauka, zaljubljen u selo, a svjestan njegovih golemih problema, razmišlja kako ga izvući iz duboke krize u koju je zapalo. Pritom nezadovoljan i znanstvenicima koji samo konstatiraju rapidno propadanje i nestanak, gašenje sela a ne vide realan izlaz iz te "nesreće", a nezadovoljan i službenom državnom politikom koja je i dovela selo na rub propasti, u svome je članku Može li zamrlo selo da oživi (str. 11-12) uputio Poziv na razgovor, titulirajući ga na "Poštovane kolege". Uz priloženi poziv Bogdanović je iznio i svoje kritičke objekcije, dakle svoje zamjerke znanstvenicima (protiveći se njihovu isključivo scijentističkom pristupu selu i seljacima, hladnoj statistici i goloj empiriji), koji dobro uočavaju razloge propadanja sela, ali su pritom stereotipni i nerealni, te previše "udaljeni i od sela, i seljaka i građana sa sela, i seljaka u gradu, i od vlasti, i od politike”. Oštre zamjerke je adresirao i na političare koji su godinama svjesno podređivali sudbinu ruralnih u korist urbanih sredina, što je dovelo do depopulacije sela. Istinita je i njegova konstatacija da u napuštenom selu danas žiteljima treba više "lekova nego hleba. I razgovora, dabome!” U istom kritičkom tonu Bogdanović nastavlja i u tekstu Selo neveselo (str. 13-20) u kojemu problematizira sintagmu "što znači i čemu revitalizacija sela", čime je još više isprovocirao znanstvenike da se sa svojim viđenjem kako riješiti nasušne probleme sela, odazovu ponuđenom pozivu na razgovor.

Kao odgovore na svoj poziv, Bogdanović je dobio petnaest što autoriziranih a što neautoriziranih odgovora od sociologa, ekonomista, politologa, filologa, književnika, pa ih je u ovom zborniku i objavio. Dio radova je pisan u nostalgičnom tonu ("selo u uspomenama"), poput napisa akademika Slobodana Remetića (Promeniti odnos prema blebu, str. 21-24), te prof. dr. Dragoljuba Đorđevića (Selo moje neveselo: raštrkane misli, str. 41-47). Drugi su pisali više u stilu "selo, mjesto življenja", uočavajući realne društveno-ekonomske probleme u ruralnim sredinama, te nastojeći sugerirati izlaz iz te duboke krize u koju je zapalo selo i njegovi žitelji. Svojim serioznim kritičkim osvrtom posebnu pažnju plijeni neautorizirani tekst Milovana Mitrovića: (Ono što se nije dogodilo slučajno ne može se ispraviti spontano), str. 6974. (Naslov je stavljen u zagrade jer je autor ove primjedbe uputio kao pismo kolegi, a ne kao članak za objavljivanje.)

U odgovoru na ponovljeni Bogdanovićev poziv, a ne želeći da se njegov odgovor objavi u knjizi, Mitrović je dao izrazito objektivnu kritiku uzroka koji su doveli selo i poljoprivredu u današnje stanje. On je - poput Bogdanovića - jednako nezadovoljan načinima znanstvenog pristupa toj problematici, a još konkretije primjebe upućuje 
na ulogu države. Ovaj prof. dr. socioloških znanosti na Beogradskom univerzitetu, svoje je viđenje izlaska iz postojeće krize izložio u nekoliko bitnih sugestija: prvo, novu agrarnu politiku usmjeriti na sinhronizirane reforme na globalnom i lokalnom planu, u cilju zaštite poljoprivrednog zemljišta i vode, u čemu bi značajnu ulogu imale agrarne institucije u sprezi s organiziranim i udruženim seljacima; drugo, provesti socijalnu reformu vodeći računa o demografskoj održivosti i alternativnoj populacijskoj politici; treće, provesti političku reformu u selu u smislu osnaživanja mjesne, lokalne i općinske samouprave te inzistirati da seljaci budu uključeni u općinsku skupštinu; četvrto, provesti kulturnu reformu u selu kroz reformu školstva, obrazovanje poljoprivrednika i mladih seljana, kroz centre za savjetodavnu službu, TV i radioemisije te do internetskog atlasa Srbije; oživjeti seoske domove kulture, umjetnička i sportska društve; peto, osnažiti zavičajnu mrežu, zavičajni savjet, kako bi bivši žitelji sela sa svojim iskustvima pomogli svome zavičaju sukladno njihovu profesionalnom statusu. Inače, Mitrovićeva je osnovna postavka: "Seljakom se ostaje, a ne postaje" (str. 69). Ovi razboriti savjeti su primjenljivi za obnovu svih zapuštenih seoskih sredina, pa smo im zato i poklonili veću pozornost.

Kao zaključak, za sve radove u ovome zborniku mogla bi se dati atributivna oznaka: pisani su s određenom dozom senzibilnosti, nostalgije za selom kojega svi pamte iz svoga djetinjstva, sela koje je živjelo "punim plućima" i bilo sebi samodovljno i samoodrživo, u stilu izrečene mudrosti da se "seljakom ostaje", a da "selo selom čine rod i običaji". Ovo današnje selo, napušteno od seljaka i seljana te zapuštenih oranica i praznih staja, doživljava se s gorčinom u duši. U istom stilu i recenzeti su pomalo skeptični u očekivanju skorih promjena u pograničnim selima istočne i jugoistočne Srbije. Recenzent dr. Đokica Jovanović napominje: "Na koncu, dobar je ovaj Bogdanovićev zbornik. Neće on ni za jotu poboljšati stvari ...", ali ipak cijeni što su autori tekstova ipak ukazali na to "koje dobro leži u zakorovljenim seoskim livadama, utrinama, njivama ... To je dobro poput dukata koji seljak nađe u polju ...". Drugi je recenzent, Obren Ristić, ipak optimističniji: "Dragocenije je međutim, što je svaki autor ponudio i neko rešenje, od minimalnog, na nivou kuće i okućnice, do državnog i nacionalnog". Hvaleći njihove realistične procjene, Ristić drži da su autori ponudili "više sjajnih ideja koje vraćaju nadu u sposobnost naroda da oživi i transformiše tradicionalnu socijalnu zajednicu - selo, zasnovanu na radu na sopstvenom posedu, u prirodnim okolnostima, ali u izmenjenim društvenim, političkim, tehničkim pa i međunarodnim okolnostima ..." (citati s poleđne korica). A sva sugerirana rješenja upućuju na jaču povezanost poljoprivrednih proizvođača i otkupnika njihovih proizvada te jaču intervenciju države u obliku subvencija. Dakle, ustaljivanje prakse koju su seljaci poznavali između 1980-ih i 1990-ih godina. U nekom kontekstu izložena je i moguća sugestija koja bi mogla pomoći oživljavanju sela. Naime, ako je svojedobno protežiranje jugoslavenske industrije uništilo selo isisavajući iz njega vitalnu radnu snagu, može li danas posrnula industrija oživjeti selo vraćajući mu propalo radništvo poniklo iz ruralnih sredina?

Na kraju sadržajne analize parcijalnog dijela studija o pograničnim selima istočne i jugoistočne Srbije što su ih objavili niško-beogradski znanstvenici, ne mogu se - ali s nekom tugom - oduprijeti želji za usporedbom zanesenjaštva ovih istraživača s nekadašnjim elanom mlade i agilne ekipe ruralista i agroekonomista okupljenih 
oko tzv. zlatne ruralnosociološke škole u Zagrebu. Naime, ranih 1960-ih godina zagrebačka je ekipa - u Agrarnom institutu - pokrenila brojne, kapitalne projekte usmjerene na empirijska istraživanja društveno-ekonomskih odnosa i procesa u selu i poljoprivredi diljem ondašnje Jugoslavije. Među istraživačima bio je i dio autora angažiranih na ovom niškom projektu, poput poznatoga beogradskoga ruralnog sociologa Đure Stevanovića i prof. dr. Ljubiše Mitrovića. Nažalost, zagrebačka se ekipa razišla i raspala, a istraživanja o problemima sela i poljoprivrede u Hrvatskoj u ovim izuzetno kriznim vremenima potpuno su zamrla. Zato sve čestitke dr. Đorđeviću i njegovoj ekipi na uloženom trudu i postignutim rezultatima na analiziranom istraživačkom projektu.

Mr. sc. Bosiljka Milinković Zagreb, Hrvatska 